\title{
Determination of minimum effective doses of luteinizing hormone and human chorionic gonadotropin for intrafollicular treatment to induce ovulation in dairy heifers
}

\author{
Jana Malá1, Jean-Francois Beckers², Noelita Melo de Sousa², Eva Indrová1, Miloslava Lopatářová1, \\ Radovan Doležel ${ }^{1}$, Helena Ševelová ${ }^{\text {, Svatopluk Čech }}{ }^{1}$ \\ ${ }^{1}$ University of Veterinary and Pharmaceutical Sciences, Faculty of Veterinary Medicine, \\ Ruminant and Swine Clinic, Brno, Czech Republic \\ ${ }^{2}$ University of Liege, Faculty of Veterinary Medicine, Laboratory of Physiology of Animal Reproduction, Liege, Belgium
}

Received October 22, 2012

Accepted August 28, 2013

\begin{abstract}
The aim of this study was to determine the minimum effective intrafollicular doses of luteinizing hormone and human chorionic gonadotropin in order to induce ovulation in cycling dairy heifers that have not yet been adequately established. Application of 10, 5, 1, 0.5, 0.1, 0.01 and 0.001 $\mu \mathrm{g}$ luteinizing hormone as well as $10,1,0.1,0.01$ and 0.001 international units (IU) of human chorionic gonadotropin in dominant follicles was performed on day 7 of the oestrous cycle. Control animals were given luteinizing hormone $(12.5 \mathrm{mg}$ and $25 \mathrm{mg}$ ) or human chorionic gonadotropin (2000 IU) intravenously. Accessory corpus luteum on day 14 of the oestrous cycle was considered as an evidence of ovulation. Ovulation was observed in 2 out of 3 heifers in each treatment group $(\mathrm{n}=3)$ after administration of $10-0.1 \mu \mathrm{g}$ luteinizing hormone (except for $0.5 \mu \mathrm{g}-$ ovulation in 3 of 3 heifers), in all heifers after administration of 10-0.01 IU human chorionic gonadotropin as well as in all control heifers. Administration of $0.01 \mu \mathrm{g}$ and $0.001 \mu \mathrm{g}$ luteinizing hormone as well as of $0.001 \mathrm{IU}$ human chorionic gonadotropin did not result in ovulation. Higher progesterone concentration on day 14 vs. day 7 of the oestrous cycle was found after all treatments. Nevertheless, the differences were significant $(P<0.05)$ only after intrafollicular treatments with 5,1 and $0.001 \mu \mathrm{g}$ luteinizing hormone as well as 10,1 and 0.01 IU human chorionic gonadotropin. In conclusion, minimum efficient doses for intrafollicular treatment of the dominant follicles in cycling heifers capable of inducing ovulation were $0.1 \mu \mathrm{g}$ of luteinizing hormone and $0.01 \mathrm{IU}$ of human chorionic gonadotropin. This is the first study describing the intrafollicular luteinizing hormone administration in cycling dairy heifers.
\end{abstract}

Intraovarian injection, ovum pick-up, ultrasound-guided transvaginal ovarian puncture, accessory corpus luteum

Ultrasound-guided transvaginal intrafollicular injection of human chorionic gonadotropin (hCG) in cattle was first reported as a useful research tool by Kot et al. in 1995. Since then, intrafollicular injection of different substances such as phosphate-buffered saline or insulin-like growth factor-I (Bergfelt et al. 1998; Ginther et al. 2004; Shahiduzzaman et al. 2010) as well as intrafollicular insemination (Lopez-Gatius and Hunter 2011) have been described. In our former study, intrafollicular treatment (IFT) with luteinizing hormone (LH) injected in the dominant follicle in heifers previously treated by deslorelin implants was reported. Ovulation was proven after the intrafollicular treatment using various doses of LH (Mala et al. 2013). However, minimum effective doses of LH for IFT in comparison with IFT using hCG have not yet been adequately established.

The aim of this study was to determine the minimum efficient doses of LH and hCG for intrafollicular treatment to induce ovulation in cycling dairy heifers.

\section{Materials and Methods}

Intrafollicular treatment equipment

Intrafollicular treatment was performed using a newly developed double channel instrument enabling aspiration of the follicular fluid and subsequent IFT with exactly the same amount of solution, while the dead volume is only the volume of the needle. The instrument and intrafollicular treatment were previously described by Cech et al. (2013).

Address for correspondence:

Svatopluk Čech

Cattle and Swine Clinic, Faculty of Veterinary Medicine

University of Veterinary and Pharmaceutical Sciences Brno

Palackého 1/3, 61242 Brno, Czech Republic 
Animals, treatment and ultrasound schedule

Holstein heifers $(n=45)$ at the age of 13 months and $350 \mathrm{~kg}$ body weight were used for the experiment. Heifers were kept at commercial dairy farms under usual conditions; the experiment was approved by the ethics committee (No 82/2012). Heifers bearing the corpus luteum (CL) were synchronized by cloprostenol (500 $\mu \mathrm{g}$ i.m. pro toto, Oestrophan ${ }^{\circledR}$, Bioveta a.s., Czech Republic). After synchronization, the day when females exhibited standing oestrus was considered as day 0 (D0). On day 7 of the cycle (D7) when the first follicular wave appeared clearly, the dominant follicle was submitted to intrafollicular treatment. Mostly one follicle was present; when two follicles were found, the larger one was treated. The minimum size of treated follicle was $10 \mathrm{~mm}$. Seven different LH doses $(10,5,1,0.5,0.1,0.01$ and $0.001 \mu \mathrm{g})(\mathrm{LH}$, prof. Beckers, Universite de Liege, Belgium) and five different hCG doses $\left(10,1,0.1,0.01\right.$ and 0.001 IU) (Pregnyl ${ }^{\circledR}$, Organon, Netherlands) were administered in treatment groups, each consisting of three heifers. Follicular collapse was observed immediately after IFT in two heifers that were excluded from the trial.

Intravenous treatment was performed in control heifers using $12.5 \mathrm{mg}$ of $\mathrm{LH}(\mathrm{n}=2), 25 \mathrm{mg}$ of $\mathrm{LH}(\mathrm{n}=2$; Lutropin $^{\circledR}$, Bioniche, Canada) or $2000 \mathrm{IU}$ hCG $(\mathrm{n}=3)$.

Ovaries were scanned on D7 and D14 of oestrous cycle using a real-time B-mode ultrasound machine (SSD500, Aloka, Japan) equipped with a linear ultrasound transducer (7.5 MHz Aloka UST 5561, Japan). Development of an accessory CL was considered as a positive response after IFT.

\section{Blood sampling and progesterone assay}

Peripheral blood was obtained from vena caudalis mediana right before the treatment (D7 of the oestrous cycle) and 7 days later (D14). Plasma was immediately separated by centrifugation (5 $000 \mathrm{~g})$ and stored frozen at $-20{ }^{\circ} \mathrm{C}$. Progesterone (P4) concentrations were determined by direct radioimmunoassay (RIA) method (without extraction), as described in detail by Lopez-Gatius et al. (2007). The minimum detection limit of the P4-RIA technique used was $0.15 \mathrm{ng} / \mathrm{ml}$. The intra-assay and inter-assay coefficients of variation of P4 radioimmunoassay were $13.8 \%(3.1 \pm 0.4 \mathrm{ng} / \mathrm{ml})$ and $19 \%(2.7 \pm 0.5 \mathrm{ng} / \mathrm{ml})$ respectively.

\section{Statistical analysis}

Progesterone concentrations are presented as a mean value plus standard deviation. Data of P4 values in cases without accessory CL were not excluded. Comparison of P4 values with the animals bearing the accessory CL was not performed due to a limited number of animals. Differences between groups were analyzed using Student's paired $t$-test, Fisher's exact test and Tukey-Kramer test (pairwise comparisons for one-way layout design). Statistical difference was presented as $P<0.05$.

\section{Results}

Ovulation (accessory CL on D7) was observed in 2 out of 3 heifers after IFT at doses of $10,5,1$ and $0.1 \mu \mathrm{g}$ LH. Positive ovarian response occurred and in all animals after IFT at the dose of $0.5 \mu \mathrm{g} \mathrm{LH}$ and after i.v. LH treatment. The doses of 0.01 and $0.001 \mu \mathrm{g}$ did not lead to ovulation (Table 1).

Table 1. Positive response (accessory corpus luteum) of ovaries seven days after intrafollicular and intravenous luteinizing hormone treatment in dairy heifers.

\begin{tabular}{lclc}
\hline Treatment & LH dose $(\mu \mathrm{g})$ & $\mathrm{n}$ & Accessory CL \\
\hline IFT & 10 & 3 & 2 \\
& 5 & 3 & 2 \\
& 1 & 3 & 2 \\
0.5 & 3 & 3 \\
& 0.1 & 3 & 2 \\
& 0.01 & 3 & 0 \\
& 0.001 & 3 & 0 \\
Control i.v. & 12.5 & 2 & 2 \\
& 25 & 2 & 2 \\
\hline
\end{tabular}

LH - luteinizing hormone, CL - corpus luteum, IFT - intrafollicular treatment, i.v. - intravenous treatment
Positive ovarian response was observed in all heifers (3 out of 3 ) after IFT at doses of $10,1,0.1$ and $0.01 \mathrm{IU}$ hCG as well as after intravenous hCG treatment. The dose of $0.001 \mathrm{IU}$ did not lead to ovulation (Table 2).

In terms of all positively responding groups, total efficiency of IFT using LH and hCG was $73.3 \%$ (11 out of 15 ) and $100 \%$ (12 out of 12), respectively. However, the difference was not significant $(P>0.05)$.

Increased progesterone
concentrations on D14


Table 2. Positive response (accessory corpus luteum) of ovaries seven days after intrafollicular and intravenous human chorionic gonadotropin treatment in dairy heifers.

\begin{tabular}{lccc}
\hline Treatment & hCG dose (IU) & $\mathrm{n}$ & Accessory CL \\
\hline IFT & 10 & 3 & 3 \\
& 1 & 3 & 3 \\
& 0.1 & 3 & 3 \\
& 0.01 & 3 & 3 \\
& 0.001 & 3 & 0 \\
Control i.v. & 2000 & 3 & 3 \\
\hline
\end{tabular}

hCG - human chorionic gonadotropin, CL - corpus luteum, IFT - intrafollicular treatment, i.v. - intravenous treatment

Table 3. Progesterone concentrations $(\mathrm{ng} / \mathrm{ml})$ on day 7 and day 14 of the oestrous cycle (day of intrafollicular treatment and seven days later) using different doses of luteinizing hormone and after i.v. luteinizing hormone treatment.

\begin{tabular}{llc}
\hline Treatment & \multicolumn{1}{c}{ D7 } & D14 \\
\hline IFT $10 \mu \mathrm{g} \mathrm{LH}$ & $4.38 \pm 1.21$ & $7.39 \pm 1.52^{\mathrm{a}, \mathrm{b}}$ \\
IFT $5 \mu \mathrm{g} \mathrm{LH}$ & $2.09 \pm 0.24$ & $12.82 \pm 1.32^{\mathrm{a}, \mathrm{b}^{*}}$ \\
IFT $1 \mu \mathrm{g} \mathrm{LH}$ & $4.29 \pm 1.05$ & $14.61 \pm 2.74^{\mathrm{a}^{*}}$ \\
IFT $0.5 \mu \mathrm{g} \mathrm{LH}$ & $4.39 \pm 0.2$ & $7.39 \pm 4.72^{\mathrm{a}, \mathrm{b}}$ \\
IFT $0.1 \mu \mathrm{g} \mathrm{LH}$ & $2.75 \pm 0.53$ & $5.94 \pm 1.89^{\mathrm{b}}$ \\
IFT $0.01 \mu \mathrm{g} \mathrm{LH}$ & $2.71 \pm 2.03$ & $5.9 \pm 1.43^{\mathrm{b}}$ \\
IFT $0.001 \mu \mathrm{g} \mathrm{LH}$ & $2.68 \pm 1.09$ & $7.45 \pm 1.54^{\mathrm{a}, \mathrm{b}^{*}}$ \\
i.v. $12.5-25 \mathrm{mg} \mathrm{LH}$ & $3.07 \pm 1.17$ & $9.11 \pm 0.77^{\mathrm{a}, \mathrm{b}}$ \\
\hline
\end{tabular}

IFT - intrafollicular treatment, LH - luteinizing hormone, ${ }^{\mathrm{a}, \mathrm{b}}$ values in D14 column are significantly different $(P<0.05)$, *values in rows are significantly different $(P<0.05)$, i.v. - intravenous treatment

Table 4. Progesterone concentrations $(\mathrm{ng} / \mathrm{ml})$ on day 7 and day 14 of oestrous cycle (day of intrafollicular treatment and seven days later) using different doses of human chorionic gonadotropin and after i.v. human chorionic gonadotropin treatment.

\begin{tabular}{lcc}
\hline Treatment & D7 & D14 \\
\hline IFT 10 IU hCG & $4.07 \pm 1.57$ & $13.82 \pm 2.84 \mathrm{a}, \mathrm{b}^{*}$ \\
IFT 1 IU hCG & $4.37 \pm 1.88$ & $12.19 \pm 0.98 \mathrm{a}, \mathrm{b}^{*}$ \\
IFT 0.1 IU hCG & $2.37 \pm 0.64$ & $11.33 \pm 3.85 \mathrm{a}, \mathrm{b}$ \\
IFT 0.01 IU hCG & $2.67 \pm 0.25$ & $7.33 \pm 0.52 \mathrm{~b}^{*}$ \\
IFT 0.001IU hCG & $2.85 \pm 1.6$ & $6.73 \pm 1.02 \mathrm{~b}$ \\
i.v. 2000 IU hCG & $4.9 \pm 1.55$ & $18.93 \pm 4.78 \mathrm{a}$ \\
\hline
\end{tabular}

IFT - intrafollicular treatment, hCG - human chorionic gonadotropin, a,b values in D14 column are significantly different $(P<0.05)$, * values in rows are significantly different $(P<0.05)$, i.v. - intravenous treatment compared to D7 (immediately before treatment) were found after all treatments. The differences were significant $(P<0.05)$ in groups of heifers treated with intrafollicular application of 5, 1 and 0.001 $\mu \mathrm{g}$ LH (Table 3) and in groups of heifers treated with intrafollicular application of 10,1 and $0.01 \mathrm{IU}$ hCG (Table 4). In addition, the progesterone concentration on $\mathrm{D} 7$ in heifers treated with $1 \mu \mathrm{g}$ LH was significantly $(P<0.05)$ different from heifers treated with $0.1 \mu \mathrm{g}$ and $0.01 \mu \mathrm{g} \mathrm{LH}$ and progesterone concentration on D7 in heifers intravenously treated with 2000 IU hCG was significantly $(P<0.05)$ different from heifers treated with intrafollicular injection of $0.01 \mu \mathrm{g}$ and $0.001 \mathrm{IU}$ hCG.

\section{Discussion}

The effects of different doses of intrafollicular administration of $\mathrm{hCG}$ as well as the technical aspects of IFT were described in the first report concerning ultrasound-guided intrafollicular injection (Kot et al. 1995). The effect of intrafollicular injection of LH in heifers previously treated with deslorelin was recently evaluated by Mala et al. (2013). However, minimum effective intrafollicular doses of LH in comparison with intrafollicular administration of hCG in cycling heifers were not established. In this experiment, the range of hCG doses was determined with regard to an earlier 
study (Kot et al. 1995) in which precise calculations of hCG doses for IFT were described. The effective intrafollicular dose was approximately $10000 \times$ lower than the systemic dose allowing ovulation ( $0.01 \mathrm{IU}$ hCG). The range of LH doses was established with regard to our previous study in which the IFT with doses of 10,5 and $1 \mu \mathrm{g}$ LH were able to induce ovulation, whereas the dose of $0.01 \mu \mathrm{g} \mathrm{LH}$ was not followed by ovulation in dairy heifers treated by deslorelin (Mala et al. 2013). Based on these data, it was decided to use an array of decreasing doses of LH (from 10 to $0.001 \mu \mathrm{g}$ ) and hCG (from 10 to $0.001 \mathrm{IU}$ ). The results were not compared with the effect of IFT with saline, as its inability to induce ovulation in dairy cows was proved sufficiently (Cech et al. 2013).

Intrafollicular treatment using $\mathrm{LH}$ and hCG in the abovementioned doses proved to be highly efficient in inducing ovulation in cycling heifers. High efficiency of $66.7 \%$ was found after administration of 10,1 and $0.1 \mu \mathrm{g}$ of $\mathrm{LH}, 100 \%$ efficiency was observed after administration of $5 \mu \mathrm{g} \mathrm{LH}$ as well as $100 \%$ efficiency was noted after administration of $10,1,0.1$ and $0.01 \mathrm{IU}$ hCG. Only doses of 0.01 and $0.001 \mu \mathrm{g} \mathrm{LH}$ and $0.001 \mathrm{IU}$ hCG failed to induce ovulation. The differences among separate groups were not significant due to insufficient number of animals. Because of the limited number of animals in the groups we compared a total efficiency of IFT with different doses of LH and hCG. After estimation of the minimum effective doses we involved only effective doses into the comparison.

Overall, total efficiency in positively responding groups was numerically lower after LH IFT $(73.3 \%)$ compared to hCG IFT (100\%). These differences are remarkable but difficult to explain. Unsuccessful treatments could not be caused by technical problems with IFT, as all treated heifers enrolled in the study showed a clear turbulence in treated follicles and, at the same time, intrafollicular injections were performed gently and without any difficulties. All treated follicles were prepared as per the same synchronization protocol and they were in the same maturation stage. In addition, higher efficiency of LH was found in the previous study, where all heifers treated by deslorelin showed ovulation after intrafollicular treatment at the dose of 5 as well as $10 \mu \mathrm{g} \mathrm{LH}$ (Mala et al. 2013). The efficiency might be affected also by different half-life of LH and hCG. And that is why lower efficiency of LH in comparison with hCG in this study should be confirmed with a larger number of treated animals. Efficiency of IFT treatment with hCG in the present study was similar to that previously described in the study by Kot et al. (1995). The results of the present study confirmed the same minimum effective dose of 0.01 UI hCG for intrafollicular administration.

Kot et al. (1995) described ovarian cysts after IFT which was not followed by ovulation. However, in our study we did not observe the occurrence of ovarian cysts in any heifer. Post-treatment ultrasonography of CLs was typical, except for two heifers after IFT $(1 \mu \mathrm{g} \mathrm{LH}$ and $0.1 \mathrm{IU} \mathrm{hCG})$ and 1 heifer after intravenous administration of $12.5 \mathrm{mg}$ LH. Accessory corpora lutea of these heifers contained a large cavity and a very thin (1-2 mm) layer of luteal tissue. Although these cases were classified as a positive response, the structures themselves were not an unambiguous evidence of ovulation due to the possibility of luteal cysts.

Higher progesterone concentrations were found on D14 of the oestrous cycle compared to D7 after all treatments. The differences were significant in groups of heifers treated with 5, 1 and $0.001 \mathrm{LH}$ and in groups of females treated with 10, 1 and $0.01 \mathrm{IU}$ hCG. Evaluation of progesterone concentrations was difficult due to the limited number of animals in the experimental groups and to large variability of progesterone values. The increase of progesterone could be caused by secretion of accessory corpora lutea and/or by increased secretory activity of original CL after the treatment. Significant increase of progesterone in heifers without ovulatory response after IFT with $0.001 \mu \mathrm{g}$ LH proved the importance of secretory activity of original CL in progesterone concentration after the treatment. Increased progesterone concentrations due to accessory corpora lutea and/or 
higher secretory activity of original CL after GnRH administered to heifers or cows within several days after ovulation were described by Garcia-Ispierto and Lopez-Gatius (2012) and Kasimanickam et al. (2011).

Progesterone concentration on D14 of the oestrous cycle (seven days after IFT) was significantly higher in heifers treated with $1 \mu \mathrm{g}$ LH compared to heifers treated with $0.1 \mu \mathrm{g}$ and $0.01 \mu \mathrm{g} \mathrm{LH}$. Progesterone concentration on the seventh day after intravenous administration of 2000 UI hCG (D14 of oestrous cycle) was significantly higher compared to IFT with $0.01 \mu \mathrm{g}$ and $0.001 \mathrm{IU}$ hCG. The highest absolute value of progesterone in the control group seven days after intravenous administration of hCG could be caused by the direct stimulatory effect of hCG on original CL. Progesterone concentrations after IFT showed a clear downward tendency with decreasing doses of hCG, although the heifers showed a positive ovarian response. It was assumed that higher intrafollicular doses of hormones could be followed by development of original and/or accessory corpus luteum and higher progesterone secretion. For this reason, progesterone secretion after IFT should be taken into account as the second indicator for the recommended dose of LH or hCG. Considering progesterone concentrations, the recommended minimum doses appears to be higher ( $1 \mu \mathrm{g}$ of $\mathrm{LH}$ and $10 \mathrm{IU}$ of hCG) than the dose required for induction of ovulation.

In conclusion, the minimum efficient doses for intrafollicular treatment to induce ovulation of dominant follicles in cycling heifers were $0.1 \mu \mathrm{g}$ of $\mathrm{LH}$ and $0.01 \mathrm{IU}$ of hCG. Nevertheless, the doses of $1 \mu \mathrm{g} \mathrm{LH}$ and $10 \mathrm{IU}$ hCG are recommended to ensure sufficient progesterone secretion after the treatment. Further studies on efficacy of IFT with LH and hCG as well as secretory activity of accessory corpora lutea after IFT using different doses of $\mathrm{LH}$ and hCG should be conducted with a larger number of experimental heifers.

\section{Acknowledgements}

The study was supported by IGA VFU Brno 6/2011/FVL.

\section{References}

Bergfelt DR, Brogliatti GM, Adams GP 1998: Gamete recovery and follicular transfer (GRAFT) using transvaginal ultrasonography in cattle. Theriogenology 50: $15-25$

Cech S, Mala J, Indrova E, Lopatarova M, Dolezel R, Dluhosova H, Zilka L 2013: The introduction of a doublechannel system for the intrafollicular treatment of cattle. Vet Med-Czech 58: 10-15

Garcia-Ispierto I, Lopez-Gatius F 2012: Effects of GnRH or progesterone treatment on day 5 post-AI on plasma progesterone, luteal blood flow and leucocyte counts during the luteal phase in dairy cows. Reprod Domest Anim 47: 224-229

Ginther OJ, Bergfelt DR, Beg MA, Meira C, Kot K 2004: In vivo effects of an intrafollicular injection of insulinlike growth factor 1 on the mechanism of follicular deviation in heifers and mares. Biol Reprod 70: 99-105

Kasimanickam RK, Mink MR, Nebel RL 2011: Effect of GnRH administration at day 5 or day 7 after AI on progesterone concentration, corpus luteum volume and pregnancy in lactating dairy cows. Clin Theriogenology 3: $455-459$

Kot K, Gibbons JR, Ginther OJ 1995: A technique for intrafollicular injection in cattle: Effects of hCG. Theriogenology 44: 41-50

Lopez-Gatius F, Garbayo JM, Santolaria P, Yániz J, Ayad A, de Sousa NM, Beckers JF 2007: Milk production correlates negatively with plasma levels of pregnancy-associated glycoprotein (PAG) during the early fetal period in high producing dairy cows with live fetuses. Domest Anim Endocrin 32: 29-42

López-Gatius F, Hunter RHF 2011: Intrafollicular insemination for the treatment of infertility in the dairy cow. Theriogenology 75: 1695-1698

Mala J, Beckers JF, Sousa NM, Indrova E, Lopatarova M, Dolezel R, Cech S 2013: Intrafollicular LH administration in dairy heifers treated by GnRH agonist. Vet Med-Czech 58: 81-86

Shahiduzzaman AKM, Beg MA, Palhao MP, Siddiqui MAR, Shamsuddin M, Ginther OJ 2010: Stimulation of the largest subordinate follicle by intrafollicular treatment with insulin-like growth factor 1 is associated with inhibition of the dominant follicle in heifers. Theriogenology 74: 194-201 